Seminar Nasional Teknologi Informasi dan Kedirgantaraan (SENATIK)

Vol. II, 26 November 2016, ISSN: 2528-1666

\title{
Klasifikasi Untuk Menentukan Tingkat Kematangan Buah Pisang Sunpride
}

\author{
Gracelia Adelaida Bere ${ }^{1}$, Elizabeth Nurmiyati Tamatjita ${ }^{2}$, Anggraini Kusumaningrum ${ }^{3}$ \\ Program Studi Teknik Informatika \\ Sekolah Tinggi Teknologi Adisutjipto Yogyakarta \\ 1'aurelbere24@yahoo.com, ${ }^{2}$ tamatjita@gmail.com, ${ }^{3}$ anggraini@stta.ac.id
}

\begin{abstract}
YIQ (Iuma, In-phase, Quadrature) is a color space used to transmit analog TV signal. This research is conducting a possibility test on using YIQ as color features for fruit ripeness classification, which tested on Sunpride bananas. Classification is done using $k$-NN algorithm against YIQ values of several ripeness stage. The classification process itself consists of two steps: training and testing. In the training step, values from $R G B$ color space of the images as training samples are converted into YIQ and extracted as features to form the classes, while in testing step, the test image went through the same conversion and feature extraction process, then classified using $k$-NN against the classes'features, using $k=3$ and $k=1$. There are 120 Sunpride banana images used as test objects, and the results obtained shown that the classification performance using $k=3$ for Sangat Matang class is $100 \%$, Busuk class is 66,67\%, Mengkal class is $60 \%$ and Matang class is $60 \%$. Results using $k=1$ for Sangat Matang class is $100 \%$, Busuk class is $66,67 \%$, Mengkal class is $66,7 \%$ and Matang class is $56,67 \%$.
\end{abstract}

Keywords : Classification, YIQ Color Space, Banana Sunpride, Euclidean Distance, $k$-Nearest Neighbors

\section{Pendahuluan}

Warna merupakan salah satu komponen penting dalam mengenali suatu obyek. Terdapat banyak sekali jenis warna yang dapat dibedakan dengan mata telanjang. Berbagai jenis warna tersebut dapat diklasifikasikan sehingga memudahkan kita dalam mengidentifikasi warna. Obyek - obyek yang dapat kita lihat di sekitar kita dapat ditentukan cirinya berdasarkan pada warna. Seperti buah Pisang Sunpride, dengan berpedomankan pada warna, kita dapat membedakan tingkat kematangannya hanya dengan melihat dari warna buah Pisang tersebut. Warna memungkinkan sebuah obyek seperti buah Pisang Sunpride dapat dikenali dan diidentifikasi dengan baik. Namun mata manusia sering kali tidak akurat dalam melihat tingkat kematangan dari buah Pisang, dikarenakan berbagai faktor. Contoh, faktor usia membuat berkurangnya penglihatan pada manusia dan lain sebagainya. Sehingga mata manusia tidak bisa dijadikan sebagai standar dalam menentukan tingkat kematangan. Oleh karena itu diperlukan metode atau cara yang tepat agar kita dapat dengan mudah menentukan tingkat kematangan dari buah Pisang Sunpride tersebut.

Terdapat berbagai macam algoritma dan metode yang digunakan dalam klasifikasi warna. Oleh karena warna merupakan salah satu komponen penting dalam mengidentifikasi sebuah obyek seperti buah Pisang maka penelitian ini akan menjadikan warna sebagai alat ukur dalam menentukan tingkat kematangan dari buah Pisang Sunpride. Adapun gambar warna buah Pisang Sunpride yang digunakan, diambil menggunakan kamera smart phone Asus Zenfone 5. Penelitian ini akan melakukan uji coba menggunakan algoritma k-Nearest Neighbors (k-NN) dalam Klasifikasi Warna menggunakan YIQ (Iuma, In-phase, Quadrature) color space untuk menentukan tingkat kematangan buah Pisang Sunpride. Algoritma k-NN merupakan algoritma yang biasa digunakan dalam pengklasifikasian suatu obyek, selain itu juga penelitian ini menggunakan YIQ color space merupakan warna yang biasa digunakan pada TV analog dan belum digunakan pada penelitianpenelitian sebelumnya untuk klasifikasi warna buah Pisang pada umumnya dan Sunpride khususnya. 


\section{Metode Penelitian}

\subsection{Tahapan Penelitian}

Penelitian dilakukan dengan tiga tahap secara umum yaitu Tahap membangun kelas, Tahap Ekstraksi ciri dan Tahap Pengujian (Klasifikasi). Gambar 1 di bawah ini menunjukkan Tahapan Penelitian pada klasifikasi untuk menentukan tingkat kematangan buah Pisang Sunpride.

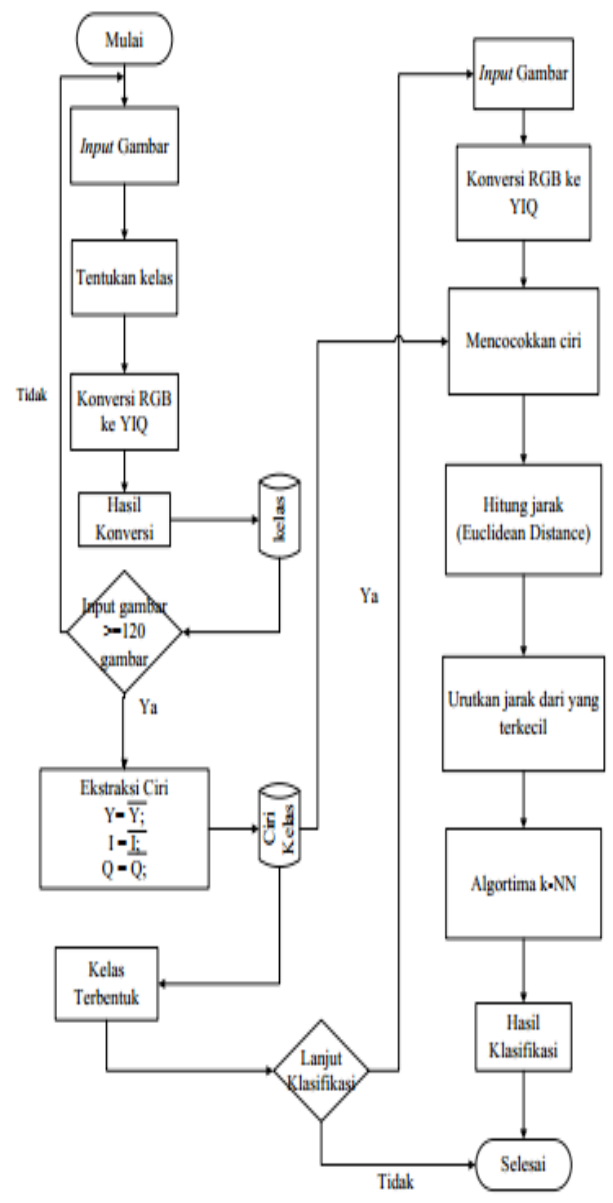

Gambar 1 Tahapan Penelitian

Klasifikasi untuk menentukan tingkat kematangan Buah Pisang Sunpride, menggunakan YIQ color space yang menjadi ciri warna setelah dikonversi dari RGB (Read, Green, Blue), ditunjukkan melalui Gambar 2. Terdapat banyak cara yang dapat dilakukan untuk menentukan tingkat kematangan buah pisang yaitu menggunakan proses perubahan kematangan buah Pisang pada beberapa tingkatan yaitu setengah matang, matang dan sangat matang pada stage 5, 6 dan 7[1].

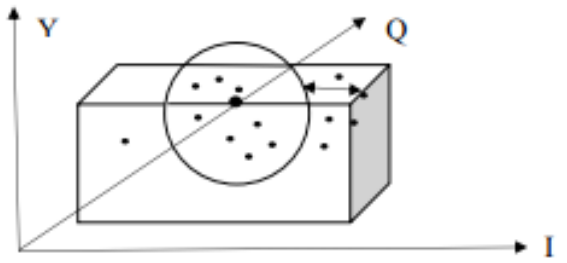

Gambar 2 YIQ Color Space

Sistem klasifikasi Pisang Sunpride ini, dapat dilihat dari luar sistem melalui 2 (dua) entitas luar yaitu Admin dan User. Sedangkan di dalam Sistem, diproses pembentukan kelas, ekstraksi ciri dan klasifikasi, seperti terlihat pada Gambar 3.

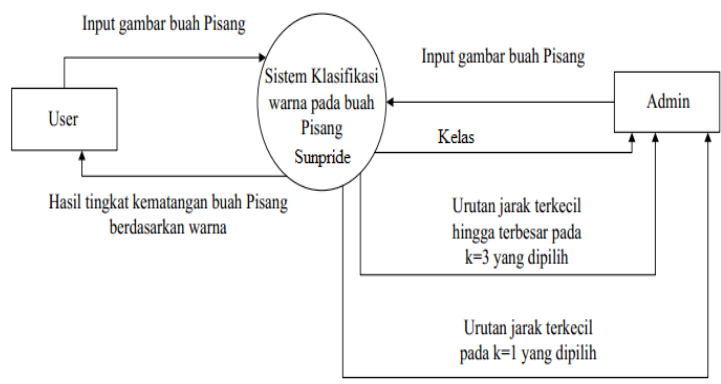

Gambar 3 Sistem Klasifikasi warna pada buah Pisang Sunpride

Tahapan-tahapan klasifikasi memerlukan tool untuk dapat dilakukan pembangunan kelas, ekstraksi ciri dan pengujian. Selanjutnya berdasarkan mesin yang digunakan (mechanical properties) untuk menentukan tingkat kematangan buah pisang. Klasifikasi buah pisang menggunakan sebuah alat yaitu zNose [2]. Aplikasi yang penulis gunakan sebagai tool dibuat menggunakan bahasa pemrograman Java. Berikut tampilan menu utama Aplikasi yang digunakan ini ditunjukkan pada Gambar 4.

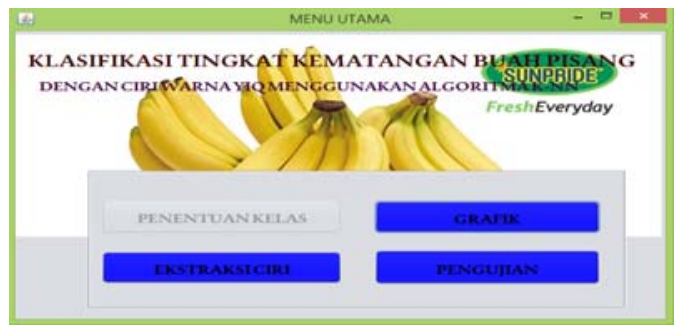

Gambar 4 Tampilan menu utama tool 


\subsection{YIQ Color Space menjadi Ciri Warna}

YIQ adalah sebuah ruang warna yang digunakan oleh sistem TV NTSC yaitu sistem warna pada televisi analog yang umumnya digunakan di Amerika, Jepang, Korea Selatan, Taiwan, Burma. Komponen Y (luma) merupakan satu-satunya komponen yang digunakan oleh televisi hitamputih. I dan Q mewakili informasi chrominance yaitu sinyal yang digunakan dalam video sistem untuk menyampaikan informasi warna dari gambar [3]. Sistem YIQ dimaksudkan untuk mengambil keuntungan dari karakteristik manusia dalam merespon warna. Fitur pada citra grayscale dan citra warna dengan hasil yang didapatkan adalah ekstraksi fitur [4] dan pada umumnya semua perangkat keras untuk citra menggunakan model warna RGB, sehingga untuk mendapatkan nilai YIQ pada sebuah gambar / citra maka di konversi terlebih dahulu menggunakan persamaan (1),(2),(3).

$\mathrm{Y}=0.299 * \mathrm{R}+0.587 * \mathrm{G}+0.114 * \mathrm{~B}$

$\mathrm{Q}=0.596 * \mathrm{R}-0.275 * \mathrm{G}-0.321 * \mathrm{~B}$

$\mathrm{I}=0.212 * \mathrm{R}-0.523 * \mathrm{G}-0.311 * \mathrm{~B}$

\subsection{Data Training dan Data Testing}

Gambar buah Pisang sunpride berjumlah 240 gambar yang terbagi atas dua bagian yaitu data training (120 gambar) dan data testing (120 gambar). Gambar buah pisang terbagi atas 4 kelas yaitu Kelas Mengkal, Kelas Matang, Kelas Sangat Matang dan Kelas Busuk. Ukuran gambar yang digunakan ialah 350x196 dengan format JPEG.

\subsection{Klasifikasi dengan Algoritma k-Nearest Neighbors}

Dalam klasifikasi sebuah obyek diperlukan ciri yang dapat membedakan setiap kelas yang diklasifikasi [5]. Algoritma k-NN adalah sebuah metode untuk melakukan klasifikasi terhadap obyek berdasarkan data pembelajaran yang jaraknya paling dekat dengan obyek tersebut. Klasifikasi dengan algoritma k-NN dengan mengelompokkan data testingberdasarkan jarak ke beberapa $\mathrm{k}$ tetangga terdekat terhadap data training. Nilai $\mathrm{k}$ yang digunakan dalam penelitian ini ialah $\mathrm{k}=1$ dan $\mathrm{k}=3$. Prinsip kerja $\mathrm{k}-\mathrm{NN}$ adalah menghitung jarak menggunakan jarak Euclidean, jarak Euclidean ini berfungsi mengukur besarnya jarak antara data yang dievaluasi dengan data training yang direpresentasikan dalam persamaan (4)

$$
d=\sqrt{\left(x_{1}-x_{2}\right)^{2}+\left(y_{1}-y_{2}\right)^{2}}
$$

Algoritma k-NN ditunjukan sebagai berikut :

1. Tentukan parameter $\mathrm{k}$

2. Hitung jarak antara data yang akan dievaluasi dengan semua pelatihan

3. Urutkan jarak yang terbentuk (urut naik)

4. Tentukan jarak terdekat sampai urutan $\mathrm{k}$

5. Pasangan kelas yang bersesuaian

6. Cari jumlah kelas dari tetangga yang terdekat dan tetapkan kelas tersebut sebagai kelas data yang akan dievaluasi.

Adapun proses pembangunan kelas (training) menggunakan 120 gambar pisang sunpride untuk masing-masing kelas sebesar 30 gambar pisang sunpride dan klasifikasi (testing) digunakan 120 gambar pisang sunpride secara acak. Proses Training dan Testing pada klasifikasi untuk menentukan kematangan buah Pisang Sunpride menggunakan YIQ color space dan algoritma k-NN ditunjukkan pada Gambar 5.

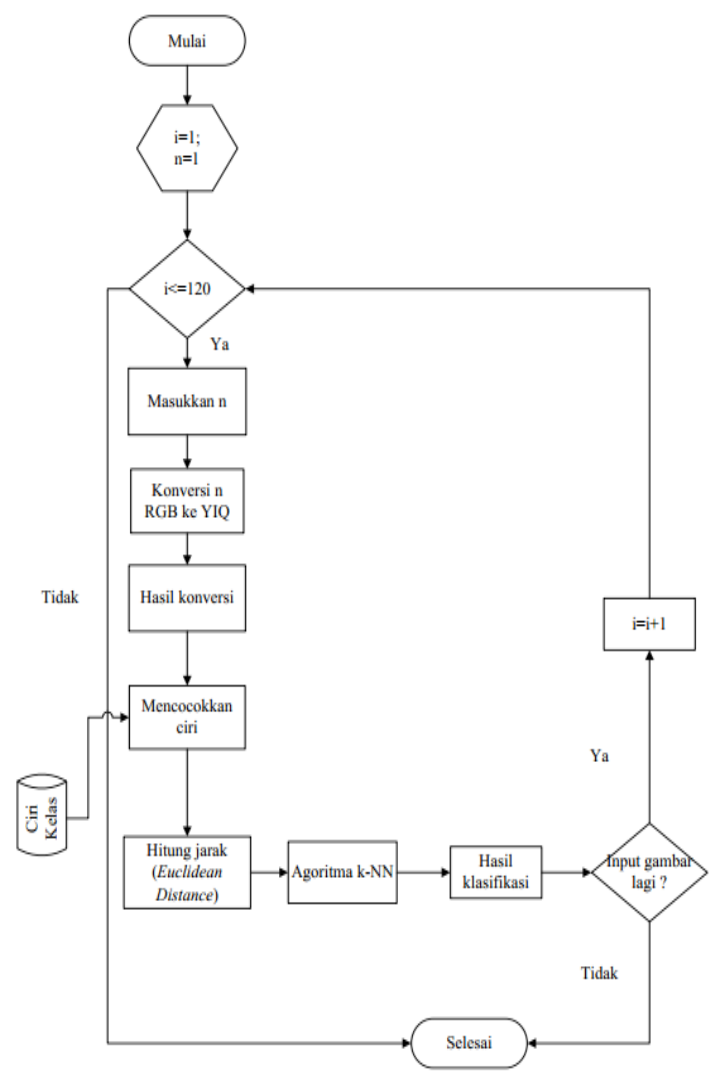

Gambar 5 Proses Training dan Testing 


\section{Hasil Dan Pembahasan}

Pengujian dilakukan pada 4 kelas yaitu kelas Mengkal, Matang, Sangat Matang dan Busuk. Dengan masing-masing kelas berjumlah 30 gambar buah pisang sunpride yang diuji menggunakan algoritma $\mathrm{k}-\mathrm{NN}$ dengan parameter $\mathrm{k}=1$ dan $\mathrm{k}=3$. Hasil pengujian untuk $\mathrm{k}=3$ dan $\mathrm{k}=1$ pada masingmasing kelas dijabarkan sebagai berikut :

$\mathbf{K}=\mathbf{3}$

1. Kelas Sangat Matang

Tabel 1 Confusion matrix Kelas Sangat Matang k=3

\begin{tabular}{|c|c|c|c|c|}
\hline KELAS & A & B & C & D \\
\hline A & 30 & - & - & - \\
\hline B & - & - & - & - \\
\hline C & - & - & - & - \\
\hline D & - & - & - & - \\
\hline
\end{tabular}

Keterangan:

A : Sangat Matang, B : Busuk, C : Matang, D : Mengkal

Berdasarkan Table 1 maka tingkat similiarity // kemiripan untuk k=3 kelas Sangat Matang sebesar $100 \%$.

2. Kelas Busuk.

Tabel 2 Confusion matrix Kelas Busuk k=3

\begin{tabular}{|l|l|l|l|l|}
\hline KELAS & A & B & C & D \\
\hline A & - & - & - & - \\
\hline B & 0 & 20 & 3 & 7 \\
\hline C & - & - & - & - \\
\hline D & - & - & - & - \\
\hline
\end{tabular}

Keterangan :

A : Sangat Matang, B : Busuk, C : Matang,

D : Mengkal

Berdasarkan Tabel 2 tingkat similiarity / kemiripan untuk k=3 kelas Busuk sebesar 66,67\%.

3. Kelas Matang

Tabel 3 Confusion matrix Kelas Matang k=3

\begin{tabular}{|l|l|l|l|l|}
\hline KELAS & A & B & C & D \\
\hline A & - & - & - & - \\
\hline B & - & - & - & - \\
\hline C & - & 3 & 18 & 12 \\
\hline D & - & - & - & - \\
\hline
\end{tabular}

Keterangan :

A : Sangat Matang, B : Busuk, C : Matang, D : Mengkal

Berdasarkan Tabel 3 maka tingkat similiarity / kemiripan untuk k=3 kelas Matang sebesar $\mathbf{6 0 \%}$.

4. Kelas Mengkal

Tabel 4 Confusion matrix Kelas Mengkal k=3

\begin{tabular}{|l|l|l|l|l|}
\hline KELAS & A & B & C & D \\
\hline A & - & - & - & - \\
\hline B & - & - & - & - \\
\hline C & - & - & - & - \\
\hline D & - & 4 & 8 & 18 \\
\hline
\end{tabular}

Keterangan :

A : Sangat Matang, B : Busuk, C : Matang, D : Mengkal

Berdasarkan Tabel 4 maka tingkat similiarity / kemiripan untuk k=3 kelas Mengkal sebesar $60 \%$.

$\mathbf{K}=\mathbf{1}$

1. Kelas Sangat Matang

Tabel 5 Confusion matrix Kelas Sangat Matang k=1

\begin{tabular}{|c|c|c|c|c|}
\hline KELAS & A & B & C & D \\
\hline A & 30 & - & - & - \\
\hline B & - & - & - & - \\
\hline C & - & - & - & - \\
\hline D & - & - & - & - \\
\hline
\end{tabular}

Keterangan :

A : Sangat Matang, B : Busuk, C : Matang, D : Mengkal

Berdasarkan Tabel 5 maka tingkat similiarity / kemiripan untuk k=1 kelas Sangat Matang sebesar $100 \%$.

2. Kelas Busuk

Tabel 6 Confusion matrix Kelas Busuk k=1

\begin{tabular}{|c|c|c|c|c|}
\hline KELAS & A & B & C & D \\
\hline A & - & - & - & - \\
\hline B & 0 & 20 & 3 & 7 \\
\hline C & - & - & - & - \\
\hline D & - & - & - & - \\
\hline
\end{tabular}

Keterangan :

A : Sangat Matang, B : Busuk, C : Matang, D : Mengkal

Berdasarkan Tabel 6 maka tingkat similiarity / kemiripan untuk $\mathrm{k}=1$ kelas Busuk sebesar 66,67\%. 
3. Kelas Matang

Tabel 7 Confusion matrix Kelas Matang k=1

\begin{tabular}{|c|c|c|c|c|}
\hline KELAS & A & B & C & D \\
\hline A & - & - & - & - \\
\hline B & - & - & - & - \\
\hline C & - & 3 & 18 & 12 \\
\hline D & - & - & - & - \\
\hline
\end{tabular}

Keterangan :

A : Sangat Matang, B : Busuk, C : Matang,

D : Mengkal

Berdasarkan Tabel 7 maka tingkat similiarity / kemiripan untuk $\mathrm{k}=1$ kelas Matang sebesar 56,67\%

4. Kelas Mengkal

Tabel 8 Confusion matrix Kelas Mengkal k=1

\begin{tabular}{|c|c|c|c|c|}
\hline KELAS & A & B & C & D \\
\hline A & - & - & - & - \\
\hline B & - & - & - & - \\
\hline C & - & - & - & - \\
\hline D & - & 4 & 8 & 18 \\
\hline
\end{tabular}

Keterangan :

A : Sangat Matang, B : Busuk, C : Matang,

D : Mengkal

Berdasarkan Tabel 8 maka tingkat similiarity / kemiripan untuk k=1 kelas Mengkal sebesar $66,67 \%$.

\section{Kesimpulan}

Hasil pengujian Algoritma k-NN dalam klasifikasi warna untuk menentukan tingkat kematangan buah Pisang Sunpride dilakukan pada 4 Kelas yaitu Kelas Sangat Matang, Kelas Busuk, Kelas Mengkal dan Kelas Matang dinyatakan berhasil dengan persentase hasil pengujian berdasarkan $\mathrm{k}=3$, tingkat similiarity /kemiripan dari 120 gambar yang diuji dengan 30 gambar untuk masing-masing kelas yang diuji, pada Kelas Sangat Matang sebesar 100\%, Kelas Busuk sebesar 66,67\%, Kelas Mengkal sebesar 60\% dan Kelas Matang sebesar 60\%. Sedangkan pengujian dengan $\mathrm{k}=1$, tingkat similiarity /kemiripan dari 120 gambar yang diuji dengan 30 gambar untuk masing-masing yang diuji pada Kelas Sangat Matang sebesar $100 \%$, Kelas Busuk sebesar $66,67 \%$, Kelas Mengkal sebesar 66,67\%dan Kelas Matang sebesar 56,67\%.

\section{Saran}

Selain menggunakan YIQ color space setelah melalui proses konversi, penelitian ini dapat dikembangkan dengan menggunakan ciri warna yang lain. Dapat pula dikembangkan klasifikasi untuk menentukan tingkat kematangan buah pisang melalui bentuk dan tekstur. Proses klasifikasinya sendiri memakai Algoritma selain dari k-NN. Sedangkan obyeknya dapat menggunakan berbagai variasi buah pisang jenis lainnya, bukan hanya Sunpride.

\section{Ucapan Terima Kasih}

Penulis mengucapkan terima kasih kepada Lembaga Penelitian, Pengembangan dan Pengabdian Masyarakat (LP3M) Sekolah Tinggi Teknologi Adisutjipto (STTA) yang telah memberi dukungan finansial terhadap penelitian ini. Kiranya penelitian ini bermanfaat bagi peneliti lain untuk pengembangan selanjutnya.

\section{DAFTAR PUSTAKA}

[1] Rajkumar,Rani et all., 2015, Classification of banana fruit maturity using zNose, Journal of Departement of Food and Agriculture, Vol.17, No. 4 : 389-396, India.

[2] Tapre dan Jain, 2012, Study of Advanced Maturity stages of banana, International Journal of Advanced Engineering Research and studies, Vol.1 No.3 : 272-274, Gujarat, India.

[3] Li, Ze-Nian dan Drew, Mark S., 2004, Fundamentals of Multimedia, Pearson Prentice Hall, New Jersey.

[4] Duda, Richard O. et all., 2000, Pattern Classification, John Wiley \& Sons, Inc., California.

[5] Tamatjita, E.N. dan Harjoko, Agus, 2014, Klasifikasi Lagu Berdasarkan Genre pada Format WAV, Jurnal IJCCS, Vol.8, No.2: 145-154, Yogyakarta. 